University of Nebraska - Lincoln

DigitalCommons@University of Nebraska - Lincoln

Faculty Publications from the Harold W. Manter Laboratory of Parasitology

4-1965

\title{
Automatic Solvent Exchanger
}

D. R. Viglierchio

University of California - Davis

Armand R. Maggenti

University of California - Davis

Follow this and additional works at: https://digitalcommons.unl.edu/parasitologyfacpubs

Part of the Parasitology Commons

Viglierchio, D. R. and Maggenti, Armand R., "Automatic Solvent Exchanger" (1965). Faculty Publications from the Harold W. Manter Laboratory of Parasitology. 616.

https://digitalcommons.unl.edu/parasitologyfacpubs/616

This Article is brought to you for free and open access by the Parasitology, Harold W. Manter Laboratory of at DigitalCommons@University of Nebraska - Lincoln. It has been accepted for inclusion in Faculty Publications from the Harold W. Manter Laboratory of Parasitology by an authorized administrator of DigitalCommons@University of Nebraska - Lincoln. 


\title{
AUTOMATIC SOLVENT EXCHANGER
}

\author{
D. R. Viglierchio AND A. R. MaggentI \\ Department of Nematology, University of California, Davis
}

\section{INTRODUCTION}

The conventional techniques available for the preparation of fresh plant and animal tissues for histological examination have been compiled in several reference reviews (Baker, 1960; Davenport, 1960; Gray, 1954; Jensen, 1926; Lee, 1946; Pease, 1960). Dehydration is usually accomplished by the successive immersion of tisssues for specific intervals in a series of mixed solvent baths of decreasing water content. A common dehydration series with aqueous ethanol would be $0,30,50,70,85,90,100$ percent ETOH. According to Baker and others (loc. cit.) the number of steps either can be reduced for rugged or tolerant tissues or increased for more sensitive tissues. Dealcoholization is usually accomplished more rapidly, with some two or three steps to a solvent miscible with paraffin or other embedding medium. The processing of tissue from water to embedding medium, effected by the use of one or more solvent series, is normally conducted manually or automatically. The automatic devices (Dilworth, 1961), others commercially available from Auto-technicon, Fisher (Tissuematon), Lipshaw (Automatic Tissue Processor) merely mechanize a limited conventional stepwise immersion of tissues in successive baths.

These techniques normally cannot be employed in the preparation of nematodes or other microscopic invertebrates for histological purposes. To obtain acceptable specimens it is necessary to increase the number of steps about threefold so that dehydration with aqueous ethanol would require series from 0-100 percent ETOH of some 20 increments. Dealcoholization would require a correspondingly greater number of bath transfers as well. Modifications to facilitate this operation have been described (Baker et al., loc. cit.); however, the procedures remain tedious and time-consuming, frequently requiring from one to two weeks. In addition the recovery of specimens of a quality acceptable for embedding is poor; a yield of the order of 20 percent is common. It is evident that an automatic dehydrator and dealcoholizer providing quality specimens in good yield would be invaluable in routine sectioning for morphological and histological purposes. 


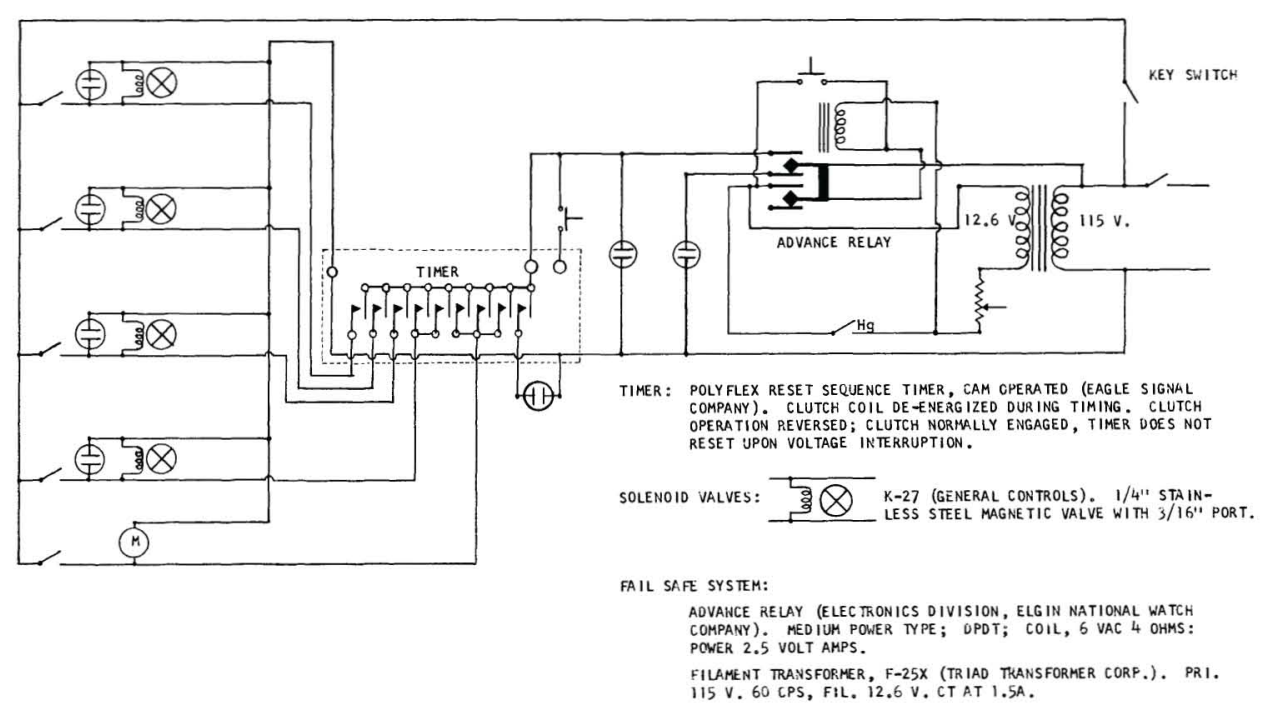

FIG. 1. Schematic circuit diagram of automatic solvent exchanger.

\section{Materials and Methods}

For convenience the automatic dehydrator and dealcoholizer or exchanger can be broken down into its component systems viz. programming, delivery, waste, stirring, heating, and fail-safe (Fig. 1-4).

\section{PROGRAMMING SYSTEM}

Since programming is time-based the polyflex timer HO64-A6-09 manufactured by Eagle Signal Company, Moline, Illinois, was selected. This unit, driven by a synchronous motor, can operate 11 independent circuits each of whose opening and closing is individually adjustable. The on and off contacts are operated by cams and the cam shaft is reset by solenoid operation of a clutch. The clutch coil is de-energized during timing and the clutch operation is reversed so that the clutch is normally engaged and the timer does not reset upon a voltage interruption.

The operational characteristics of the timer require that each step in the sequence be controlled by a separate circuit, though the identical step had already occurred in the program.

\section{DELIVERY SYSTEM}

This system essentially consists of a pressurized gas supply, a 3-way solenoid valve (ASCO Cat. No. 831421 , brass body, $1 / 8$ in. pipe, $1 / 8$ in. orifice), a solvent reservoir one liter, a needle valve (Fisher 14-630-5; Manostat NV1000, New York, N. Y.) and a delivery needle (hypodermic needle No. 25) with all components connected by appropriate tubing (Fig. 2A). Since all solvents are delivered in the same manner, only one solvent line need be described.

The low pressure gas supply is used to force solvent from one liter reservoir through the needle valve and the delivery needle. Any gas that is sparingly soluble in the solvent and does not react with it or the specimen tissue is suitable when at a pressure above ambient on the order of $50 \mathrm{~mm}$. Hg. For 

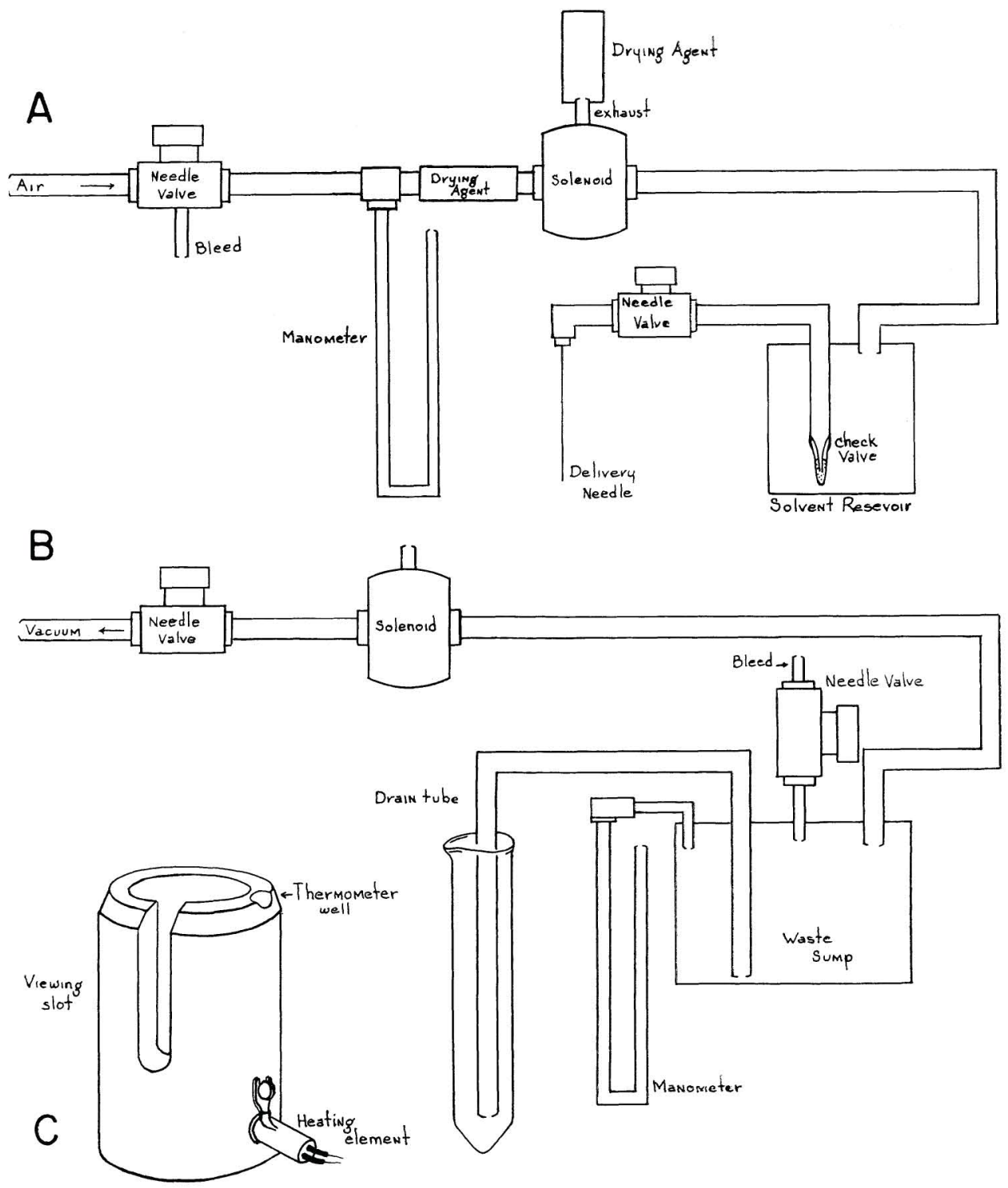

Fig. 2. Schematic diagram of solvent distribution and heater. A, fresh solvent delivery system. B, waste solvent disposal system. C, specimen vial heater.

simplicity and construction of a self-contained unit, air, pressurized by an aquarium pump was used. Since such pumps are designed to deliver larger volumes of air at higher pressures than need be utilized here, a bleed off valve and manometer are attached to the line in that order. The needle valve is to bleed off air at a rate necessary to maintain the delivery pressure desired as indicated on the mercury manometer. The gas or air then passes over a drying agent to remove moisture which would otherwise dilute the anhydrous solvents. The gas flow into the reservoir is controlled by a three-way 
SOLVENT EXCHANGER

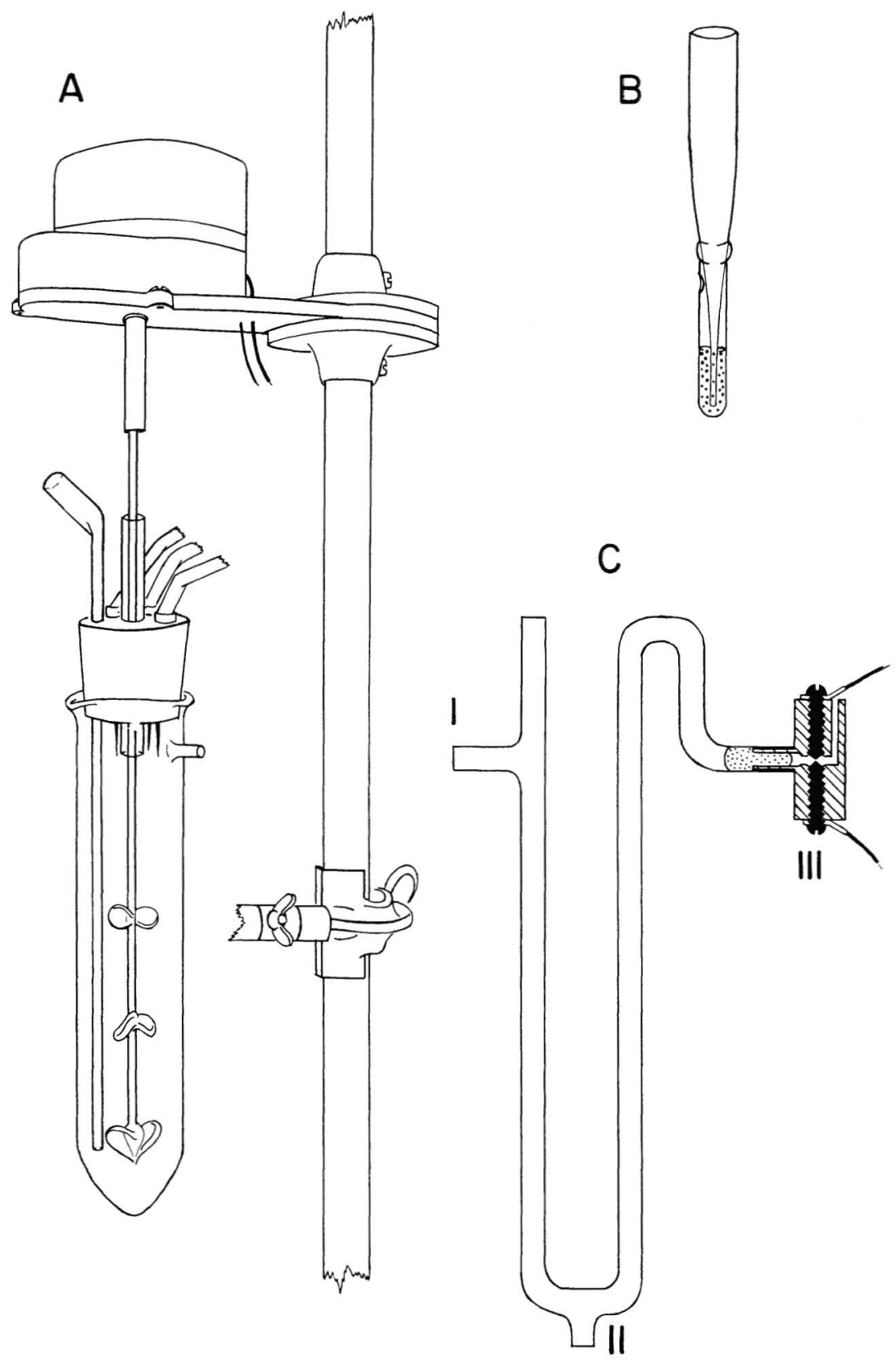

FIG. 3. Schematic diagrams: A, stirring apparatus, specimen vial with overflow tube, delivery needles, and drain tube. B, reservoir check valve. C, fail-safe assembly, I overflow tube, II overflow drain, III mercury switch. 


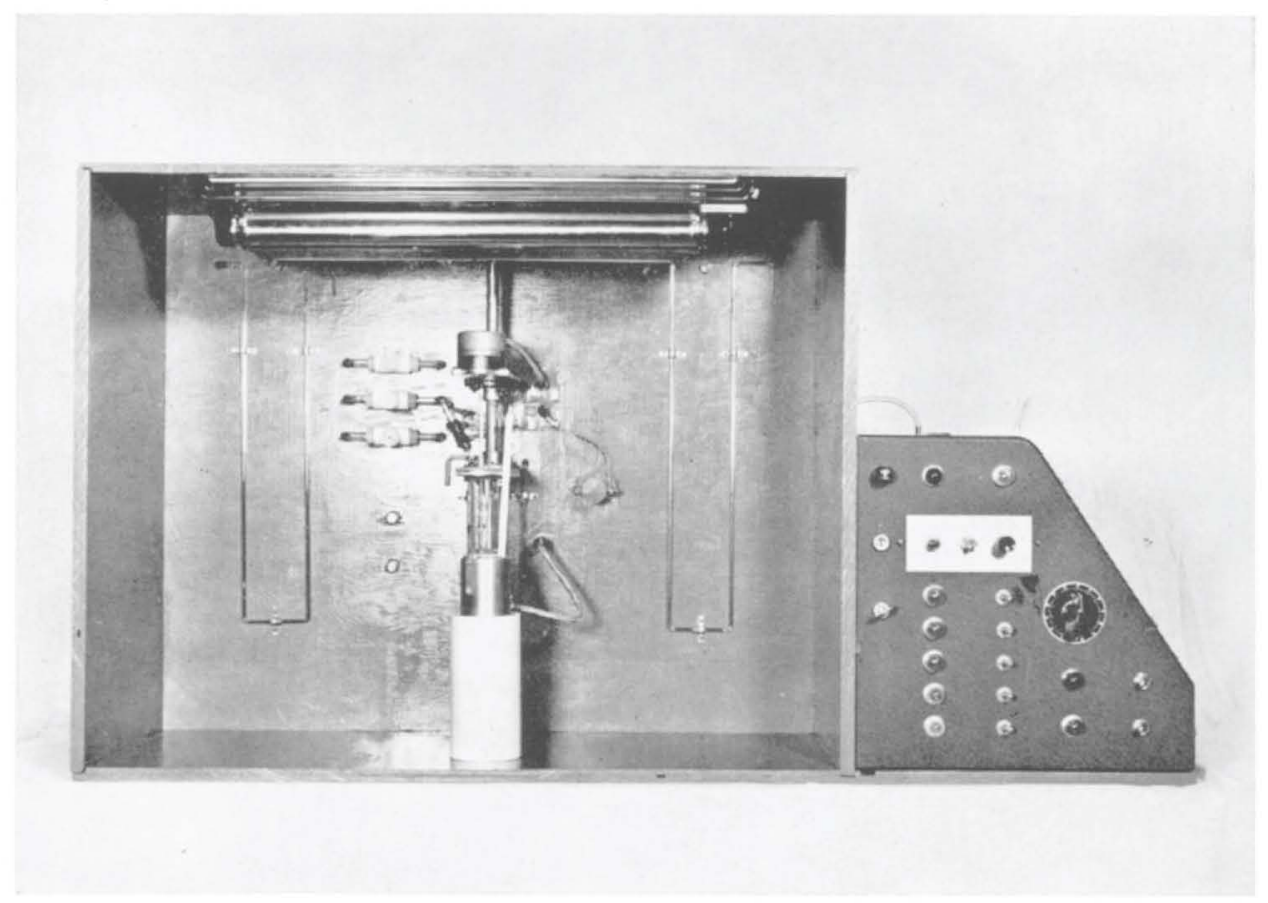

FIG. 4. Front view of operating unit.

solenoid valve. When energized, the valve allows gas to flow to the reservoir which becomes pressurized; de-energized, the valve vents to atmosphere so that the reservoir de-pressurizes and equilibrates with atmosphere. The exhaust takes place over a drying agent to prevent moisture from entering the system. A stoppered filling tube leads from the reservoir to a service center at the top of the exchanger cabinet. Upon pressurization of the reservoir the solvent flows through the check valve and out the exit tube through a needle valve, used to adjust solvent flow rate, then through the delivery needle into the specimen vial ( $50 \mathrm{ml}$. centrifuge tube with conical bottom). A mercury-operated check valve is attached to the base of the solvent delivery tube leading out of the reservoir (Fig. 2A, 3B). Upon the application of pressure to the reservoir the solvent forces the mecury up the inner tube of the valve where it flows around the mercury drop and on to the needle. As the reservoir returns to ambient pressure the weight of solvent between the delivery needle and the check valve forces the mercury back down the inner tube and up the outer column till the mercury head equalizes the back pressure of the solvent head. The amount of mercury in the valve depends upon the geometry of the valve; there must be enough to form a column exerting sufficient pressure to equalize that of the solvent head. The delivery needle, needle valve, reservoir, as well as all tubing in contact with the solvent must react neither with it nor dissolve it. Teflon, glass, or stainless steel are generally suitable for nearly all solvents. The tubing conducting the gas may be of any material sustaining the low pressure but preferably other than rubber which deteriorates in short order giving rise to leak problems. Tubing and components were assembled with screw-type fittings or close-matched slipon connections sealed with commercially available shrink-down tubing. 
WASTE SYSTEM

The drainage system consists essentially of a source for reduced pressure, a three-way solenoid valve, a one-liter waste sump and exchange vial drain-tube (Fig. 2B). Subatmospheric pressure on demand, reduces pressure in the waste sump so that ambient pressure forces the undesired liquid in the exchange vial out the drain-tube for disposal. Any safe means capable of maintaining a pressure of $75 \mathrm{~mm}$. $\mathrm{Hg}$ below ambient pressure is suitable. For practical considerations in devising a self-contained unit, an aquarium air pump was modified to develop the desired pressure. The withdrawal of gases from the waste sump is controlled by a three-way solenoid valve. Energized, the valve allows gases in the sump to pass to the vacuum pump so that the desired pressure below ambient is established; de-energized, the valve vents the sump to atmosphere so air enters and pressure equalizes. To the sump, in addition to the lines from the solenoid valve, there are affixed separate lines to a needle valve, manometer, sump waste removal connector and exchange vial. The needle valve is used to bleed in air at a rate necessary to maintain the desired reduced pressure within the sump as indicated by the mercury manometer. The sump waste removal line runs to the service center at the top of the cabinet and is used as needed to dispose of the waste solvents accumulated in the sump. The line leading from the sump to the vial drain tube is branched. One branch leads through a needle valve to the drain orifice of the fail-safe unit, the other branch leads through another needle valve to the vial drain tube. Proper manipulation of needle valves permits the disposal of waste solvent from either the vial or the fail-safe unit. In normal operation the valve on the fail-safe line is closed and that in the vial drain open. The vial drain-tube $(2 \mathrm{~mm}$. I.D.) is adjusted in its mounting so that with the vial in place after draining there will remain any desired volume of liquid in the vial (usually $2.5 \mathrm{ml}$. for our purposes). The composition of the tubing, components, and connectors must be compatible with the solvents and fulfill the requirements expressed in the delivery section preceding.

\section{STIRRING SYSTEM}

Stirring is accomplished with a direct drive unit, i.e., a paddle stirrer (Fig. 3A) unaffected by solvents coupled directly to the rotating motor shaft. The reduction gear assembly of a $115 \mathrm{~V}, 60$ cycle, 3-Watt synchronous timer motor was removed and the stirrer coupled directly to the rotor by means of a flexible connector. The stirrer thereby rotating about $240 \mathrm{RPM}$ provided adequate mixing without vortexing or undue turbulence and shearing.

\section{HEATING SYSTEM}

The block heater is constructed from two-inch aluminum rod (Fig. 2C). A cavity is machined out of the rod to accommodate the specimen vial snugly. The bottom of the aluminum block is drilled out to accommodate a small heating element (120V, 50 Watts ). In addition a thermometer well is drilled in the heater block wall parallel to the vial axis. The heating element is fitted with a three-wire lead to a banana jack attached to the cabinet. The jack in turn is wired to a variable transformer mounted on the control panel and to ground (Fig. 4). The variable transformer enables voltage adjustment for selection of a desired vial bath temperature. The heater circuit is such that the heater may be operated manually or automatically with the timer. 


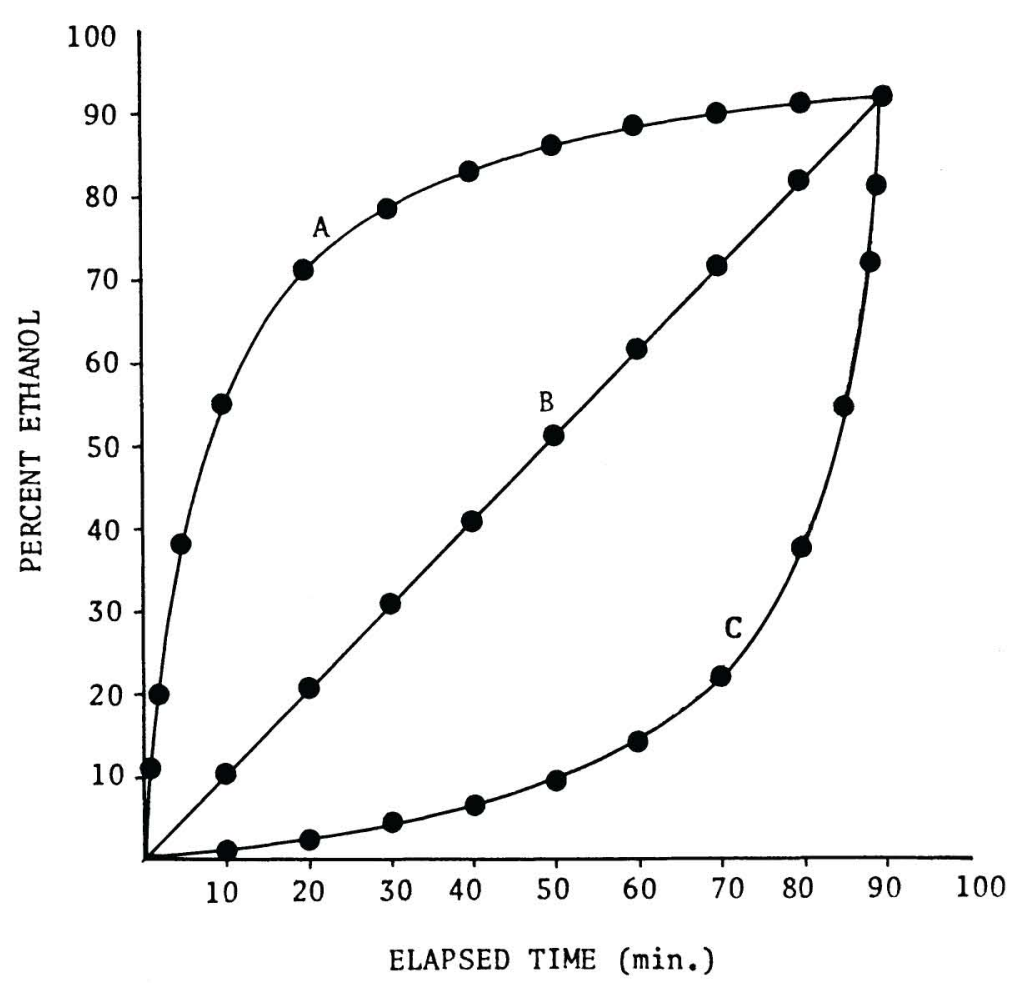

FIG. 5. Concentration: time curves of solvent exchange showing change in the rate of change of concentration. A, negative. B, constant-zero. C, positive.

\section{FAIL-SAFE SYSTEM}

Power ( $120 \mathrm{~V} \mathrm{AC}$ ) is supplied to the exchanger through one of the contacts of a $6.3 \mathrm{~V}$ AC normally open, double pole, double-throw relay (Fig. 1). The relay coil is energized to the closed position through a momentary supply of low voltage power by means of a push button; it is maintained energized thereafter by low voltage power through the other relay contact. A pressure operated mercury switch (Fig. 3C) is used to short circuit momentarily the low voltage power supplied to the relay coil through one of the relay contacts in the event of operational failure of the exchanger. The pressure switch is operated through pressure transmission of an overflow head of solvent from the specimen vial. A side arm is attached near the top of the vial at about the $35 \mathrm{ml}$. level. This side arm is coupled to one end of a U-tube attached to the cabinet while the mercury switch is coupled to the other. In the event of instrumental failure resulting in an oversupply of solvent to the vial, the overflow runs into the U-tube until the column of solvent develops sufficient head $(\sim 10 \mathrm{~cm}$.) to move the mercury droplet across the electrodes to short circuit the low voltage power supplied to the relay coil which immediately opens to interrupt $120 \mathrm{~V}$ AC power. The open arm of the U-tube (Fig. 3C) above inlet I allows the overflow from the specimen vial to flow into lower portions of the U. Outlet II is merely a drain outlet attached to the waste system (already described) and permits ready removal of overflow solvent for re-activation of the fail-safe system. The mercury pressure switch body (Fig. 3C III) is constructed from $1.5 \mathrm{~cm}$. 
diameter plexiglass rod. The mercury cavity and vent holes are $2 \mathrm{~mm}$. in diameter. The electrodes are brass screws machined to a point and threaded in the plexiglass as shown (Fig. 3C). The attachment of the leads is indicated in the wiring diagram (Fig. 1).

The assembled unit is shown in figure 4 . The external measurements of the box are $28 \times 22 \times 18$ inches; internally the box is divided by the mounting board into two compartments. The front compartment (10 in. deep) contains the valve controls, manometers, and specimen apparatus. The rear compartment ( 8 in. deep) houses the drying tubes, reservoirs, air, and vacuum supplies. Attached to the right side is a 12- $\times 12-\times 18$-inch sloping panel cabinet which contains the timer, solenoids, and control wiring.

\section{Discussion}

Dehydration and infiltration of tissues with solvents miscible with embeddiig media has generally been accomplished by the transfer of the specimen into an appropriate series of solvent baths. For more sensitive tissues, e.g., insect larvae, insect eggs, nematodes, and microscopic invertebrates, the number of solvent baths in a series is increased so that the concentration change between successive baths takes place in smaller increments. The process of conducting the exchange through an ever-increasing number of baths, however, soon becomes completely unwieldy. In view of the geometrical dimensions of microscopic organisms and/or excised tissues, practical considerations would indicate the use of solvent transfer rather than specimen transfer. The Cobb Differentiator (Cobb, 1918) applied this principle by passing in sequence the components of a solvent series (previously stratified in a reservoir column) over the stationary specimen. The technique which still effects the exchange in a stepwise fashion over a period, usually two weeks, is not amenable to routine laboratroy procedure.

Specimens in the automatic exchanger are exposed to a continuously changing solvent concentration gradient by simple immersion in a bath to which a second solvent is added at a controlled rate. By controlling the addition rate of a solvent it is possible to control the rate of change of concentration in the specimen bath, e.g., in curve A (constant addition rate) (Fig. 5) the rate of change is greatest at low concentrations; in curve B the rate of change is constant and in curve $\mathrm{C}$ (mirror image of curve A) the rate of change is greatest at high concentration.

The automatic apparatus for solvent exchange described here generates a rate of change curve of type A. However, by substitution of appropriate solvent concentrations in the reservoir and changing addition rates, curves approaching type $\mathrm{C}$ can be obtained. For most tissues the exchange illustrated by type A or B curves is satisfactory. Results with very delicate tissues, e.g., some whole nematodes, can be improved by an exchange of the nature of curve $\mathrm{C}$. Both experience and experimentation have shown that with nematodes the critical exchange takes place in the range of 0-30 percent alcohol while at higher alcohol concentrations exchanges may proceed more rapidly. Being of general interest, the method of preparation for embedding in paraffin involving processing tissue through ethanol, xylene to paraffin was selected for illustration of the utility of the apparatus. Normally, nematodes suitably killed and fixed are available as a suspension in water. A reasonable number of nematodes are placed together with water in the specimen vial so that the initial volume is $2.5 \mathrm{ml}$. After the specimen vial is placed in position the sequence of operations is begun. Stirring commences followed by the addition of anhydrous ethanol at a constant rate such that $27.5 \mathrm{ml}$. are added in one and one-half hours. Stirring is then stopped to allow the specimens to settle to the bottom of the vial. After 20 minutes the 
drain system is activated to remove solvent in excess of $2.5 \mathrm{ml}$. (about 2 minutes). Stirring commences for the next cycle and the second solvent ( 50 percent by volume anhydrous ethanol-xylene) added at a constant rate such that $27.5 \mathrm{ml}$. are delivered in one hour $(0.458 \mathrm{ml} . / \mathrm{min}$. $)$. Stirring is again stopped for another 20-minute settling period before a second drain leaving $2.5 \mathrm{ml}$. of solvent. Stirring then commences for the next cycle and the third solvent, anhydrous xylene, is added at $0.458 \mathrm{ml} . / \mathrm{min}$. for one hour at which time the preparation has been completed in an elapsed period of four hours and 14 minutes. The animals are now ready for embedding in paraffin. Obviously, if the specimen volume is not negligible with respect to the solvent in which they are suspended, the appropriate corrections must be made to obtain the proper rate-change curve. The $2.5 \mathrm{ml}$. volume was selected since it was in the suitable range for concentration relations. A smaller volume would make the initial rate of change dangerously rapid; a large volume would not allow a sufficiently high exchange concentration. With rugged animals alcohol exchange could be achieved in one hour; however, the more sensitive animals appeared to suffer. For more sensitive specimens it would be possible to lengthen the exchange period, but it would be more advantageous to use a modified cycle approximating curve C. Anhydrous alcohol is used to attain a final concentration such that the residual water, after the initial drain, dissolves in the second solvent mixture of ethanol-xylene. The use of mixed solvents permits the faster addition of solvents with an even greater margin of safety than with alcohol. Though nematodes have usually settled to the bottom of the vial in about ten minutes an extra ten-minute safety margin was allowed for the smaller, slower-settling ones. It is evident that the operating time could be shortened by about one-half, but it is questionable whether the saving in time would warrant the risk. The incorporation of a heater for the specimen vial allows the operator to take advantage of higher diffusion rates at elevated temperatures for an increased exchange rate on an additional margin of safety. The apparatus has been described for the delivery, as desired, of an ethanol-xylene solvent sequence; by changing solvent reservoirs and delivery rates it may be employed for the delivery of any desirable solvent sequence to expose the specimens to a continuously changing concentration gradient.

The use of multiple methods and procedures to assure that an observation is real and not an artifact is fundamental to scientific studies. In taxonomy, morphology, histology, or histochemistry, multiplicity of techniques or procedures should be applied to ways and means of killing, fixing, dehydrating, or any operation preliminary to a microscopic observation and not only as generally occurs, to embedding and staining. The flexibility of operation available with the above-described automatic exchanger permits the facile manipulation of solvents in several ways with the inherent element of reproducibility. The automatic exchanger permits the study of a single animal microscopically in two or more ways conveniently. For example: a single specimen may be processed on the machine through alcohol and mounted in glycerine; or, further processed to xylene for clearing, returned to alcohol and mounted in glycerine; then, after a taxonomic or gross morphologic study is made, the same specimen may be returned to alcohol by the exchanger and processed for paraffin embedding and thus be studied histologically or histochemically. If desired, the animal may even be processed to propylene oxide as preparatory to embedding for study with the electron microscope.

\section{SUMMARY}

A solvent delivery and removal system has been designed and developed such that solvent exchange in specimens and tissues can be effected automatically at ambient or above ambient temperatures. The operation may be programmed so that any series of solvents 
mutually soluble in sequence may be exchanged. For convenience in calibration and flexibility the system may be operated manually.

\section{Literature Cited}

Allen, E. 1916. Cell division in the albino rat. Anat. Recd., 10(9): 570-574.

BAKer, J. R. 1960. Cytological technique. Methuen's monographs on biological subjects. London and New York, pp. 150.

Bishop, G. H. 1917. An apparatus for gradual dehydration. Trans. Amer. Microsc. Soc., 36: 27-32.

Совв, N. A. 1918. Estimating the nema population of soil. U. S. Dept. Agr., Bur. Plant Ind., Agr. Tech. Cir., 1: 1-48.

Davenport, H. A. 1960. Histological and histochemical technics. W. B. Saunders Co., Philadelphia and London, pp. 401.

Druworth, S. 1961. A new automatic machine for staining histological sections. Quar. Jour. Microsc. Sci., 102(4): 451-454.

Gray, P. 1954. The microtomist's formulary and guide. Blakiston Co., Inc., New York and Toronto. pp. 794.

HANCE, R. T. 1926. An air distributer for use in the drop method of dehydration. Stain Technology, 1: 70-71.

Jensen, W. A. 1962. Botanical histochemistry. W. H. Freeman and Co., San Francisco and London, pp. 408.

Johansen, D. A. 1940. Plant microtechnique. McGraw-Hill, New York and London, pp. 523.

LeE, B. 1946. The microtomist's vade-mecum. Blakiston Co., Philadelphia and Toronto, pp. 784 .

Lundy, J. 1960. A rapid manual method for transferring tissues through processing liquids. Stain Technology, 35(4) : 219-222.

Magath, T. B. 1916. String siphon differentiator. Trans. Amer. Microsc. Soc., 35: 245-246.

Maggentr, A. R. and Allen, M. W. 1960. The origin of the gelatinous matrix in Meloidogyne. Proc. Helm. Soc. Wash., 27(1): 4-10.

PeAse, D. C. 1960. Histological techniques for electron microscopy. Academic Press, New York and London. pp. 274. 